\title{
Sources of stress and scholarly identity: the case of international doctoral students of education in Finland
}

\author{
Sotiria Pappa ${ }^{1}$ (D) Mailis Elomaa ${ }^{2} \cdot$ Satu Perälä-Littunen ${ }^{3}$
}

Published online: 2 January 2020

(C) The Author(s) 2019

\begin{abstract}
Although stressors and coping strategies have been examined in managing stress associated with doctoral education, stress continues to have a permeating and pernicious effect on doctoral students' experience of their training and, by extension, their future participation in the academic community. International doctoral students have to not only effectively cope with tensions during their training and their socialization in their discipline but also address the values and expectations of higher education institutions in a foreign country. Considering the increase of international doctoral students in Finland, this study focuses on perceived sources of stress in their doctoral training and how their scholarly identity is involved when responding to them. The study draws on thematically analyzed interviews with eleven international doctoral students of educational sciences. The participants, one man and ten women, came from nine countries and conducted research in six Finnish universities. The principal sources of stress identified were intrapersonal regulation, challenges pertaining to doing research, funding and career prospects, and lack of a supportive network. Despite the negative presence of stress, most participants saw stress as a motivating element. However, in order for stress to become a positive and motivational force, participants had to mediate its presence and effects by means of personal resources, ascribing meaning and purpose to their research, and positioning themselves within their academic and social environment. The study argues for stress as a catalyst for scholarly identity negotiation and professional development when perceived positively.
\end{abstract}

Keywords International doctoral students $\cdot$ Scholarly identity $\cdot$ Identity negotiation · Stress · Eustress $\cdot$ Higher education

Sotiria Pappa

sotiria.s.pappa@helsinki.fi

Extended author information available on the last page of the article 


\section{Introduction}

There has recently been a surge of interest in doctoral education amidst academic discourse (e.g., Aittola 2017; Cantwell et al. 2012; Laufer and Gorup 2018), especially with the Bologna Process suggesting key aspects of educational and political importance as well as a supranational character (Baptista 2011). Yet going beyond the technical aspects of doctoral training, the personal experiences of the doctoral student have largely remained underexplored (Amran and Ibrahim 2012). One of the doctoral students' personal experiences in doctoral education that remains salient is stress. Doctoral students may be particularly susceptible to stress and precariousness, as they run a high risk of having or developing mental health problems, especially depression, due to factors like organizational policies, work-life imbalance, job demands, and career prospects outside academia (Levecque et al. 2017). Moreover, doctoral students' perceptions of their training play an important role in the success of doctoral programs (e.g., Aittola 2017). Although stressors and coping strategies have been examined in managing stress associated with doctoral education (Devonport and Lane 2014), stress continues to have a permeating and pernicious effect on doctoral students' experience of their training and, by extension, their future participation in the academic community.

Following the European models and regulations, such as the Bologna Process, the Finnish national system of doctoral education has undergone several reforms within the last decades. The reforms, including the expressed need for internationalization, have enhanced possibilities for participation in education for international doctoral students (IDS) (e.g., Aittola 2017; Peura and Jauhiainen 2018). This increase is evident in the number of IDS in education which increased from 72 students in 2007 to 138 students in 2017 (Vipunen, Education Statistics Finland 2017). The increase of IDS could partially be attributed to the fact that the core funding model of universities in Finland up to 2017 favored doctoral degrees by international students (Finnish Ministry of Education and Culture 2011). Finland has seen the increased steering of doctoral training in recent decades by actions such as using a quota of completed doctoral degrees per university as a funding criterion (see Finnish Ministry of Education and Culture 2015). As a result, the doctoral degrees - especially degrees by international students until 2017 - have gained new importance, and the work by doctoral students forms a considerable part of research in universities (e.g., Hakala 2009). Therefore, the experiences of pressure and professional development by IDS in Finnish universities becomes an issue pertinent to universities' financial and research support (see Peura and Jauhiainen 2018). Within such circumstances, this case study focuses on IDS doing educational research in Finnish universities. It explores the perceived sources of stress in their doctoral training and how scholarly identity is involved when responding to them.

\section{Theoretical framework}

\section{Scholarly identity negotiation as an emotion-imbued learning process}

Professional identity is individuals' understanding of themselves as professional subjects, influenced by personal and professional trajectories, workplace and interpersonal settings, personally held value systems and ethical standards, beliefs, and interests (Eteläpelto et al. 2014). The professional identity of doctoral students as young researchers in training is understood as scholarly identity. Scholarly identity is central to doctoral students' training, 
as it strongly engages their overall learning, aspirations, desires, and personally held views of themselves as young academics (Cotterall 2015). Research on IDS shows that their socialization, both self- and other-directed, recursively uses internal and external sources and resources in becoming agentic and internalizing institutional practices, pedagogical paradigms, behaviors, positionalities, and ways of thinking (Anderson 2017; Evans and Stevenson 2010; Pyhältö et al. 2012a; Sidhu et al. 2014).

Despite the exercise of individual agency, scholarly identity negotiation is a bidirectional process. Scholarly identity requires recognition and validation by the intellectual and institutional networks in which the doctoral student should credibly exhibit their competence in a relevant discipline (Cotterall 2015). Validation of one's scholarly identity may further be influenced by the roles emphasized in their academic environment, with doctoral students of education choosing that of the practitioner's over that of the teacher's - something which stresses the implications of practical experience within educational research (Kovalcikiene and Buksnyte-Marmienea 2015). Moreover, authority figures influence one's scholarly identity negotiation, with the supervisory and research processes bearing on the subjective experience of being a doctoral student (Baptista 2011). In effect, the intellectual and institutional networks at the university comprise the community of practice that affects how doctoral students experience themselves as scholars; they can nurture scholarly identity negotiation and provide it the space to connect to other identities (Coffman et al. 2016).

While bidirectional, the process of navigating and using networks to negotiate one's professional identity is also an emotional one. In her research with IDS, Cotterall (2013, 2015) argues that identity occupies a central role in doctoral training, as a doctoral student's current understandings and future aims are inextricably tied to their learning trajectories and thinking processes. In addition to that, developing a scholarly identity has emotional dimensions that often go unacknowledged and is a process punctuated by emotion-provoking encounters with key individuals and situations (e.g., supervisory relationship, composing the dissertation, writing in English as a second language) (Baptista 2011; Cotterall 2013; RussellPinson and Harris 2019). The emotions that need to be managed on the part of the doctoral student include stress, pressure, and uncertainty, which may be exacerbated under the evertightening financial constraints in academia and the expectation for new faculty members to exhibit more talent and productivity in relation to their predecessors (Austin 2002). In addition to that, doctoral students are expected to be mobile and flexible not only as employees of the contemporary job market (Meijers 2002) but also as researchers with future work and funding prospects (e.g., Academy of Finland criteria). This state of impermanence may heighten their perception of stress in their lives. Taking such conditions into account, examining how stress affects the negotiation of scholarly identity becomes important to doctoral students and doctoral education alike.

\section{Stress and eustress}

From a broader perspective, stress may refer to an event or succession of events that cause a response, often in the form of "distress," or to a challenge leading to a feeling of exhilaration, in the form of "good" stress (Joshi 2005). While a stressor is a stimulus event that challenges the integrity or health of the body, stress response is the body's compensatory reaction to that challenge (Lovallo 2005). In literature, stress is often described as a person's response mechanism or a survival reaction to a negative event (Baum et al. 2001; Folkman 2008; Ursin and Eriksen 2004). More particularly, stress is a response syndrome of negative affects 
which develop because of prolonged and increased pressures that cannot be controlled by an individual's coping strategies (Kyriacou 1987; Ursin and Eriksen 2004). Stress serves as a mediational process in which stressors (or demands) trigger an attempt at adaptation or resolution that results in individual distress if the organism is unsuccessful in satisfying the demands (Linden 2005). Moreover, stress can be understood as part of a sequential process in which objective environmental circumstances are appraised by the individual either as having no adaptive significance or as straining or exceed a person's adaptive resources (Lazarus and Folkman 1984; Linden 2005). Amidst environmental demands, regarded as one of the most common factors causing the stress (Shapero and Hankin 2009), responding to stress occurs at physiological, behavioral, and cognitive levels (Schneiderman et al. 2005).

The negative characteristics of stress are commonly known (Kyriacou 1987; Lazarus and Folkman 1984), yet its positive side, referred to as "eustress," is less often discussed (Mesurado et al. 2016; O'Sullivan 2011). Stress is not only seen as something "negative" when the individual is unsuccessful in satisfying personal or environmental demands but also as something "positive" when it leads to success in fulfilling such demands (Kupriyanov and Zhdanov 2014; Szalma and Hancock 2008). Reactions to stress depend upon the nature of that stress and the capacities that the exposed entity or organism can utilize to answer the challenges which this stress poses. Eustress is both the process of responding positively to stress as well as the positive outcome of this process (O'Sullivan 2011). O'Sullivan (2011) argued that, at the academic level, the positive response to stress could include studying and working to complete assignments, whereas the outcome of eustress could include productivity and successful completion of assignments and exams. This is supported by research among university students who showed eustress as a positive psychological response to academic stressors that are perceived as a challenge (Mesurado et al. 2016). Although the experience of stress may play an important role in doctoral student life, there are, to our knowledge, very few studies conducted on the phenomenon and even less concentrating on the role of stress in scholarly identity.

\section{Research questions}

The importance of scholarly identity for doctoral students as well as the institutional and social influences on it has been acknowledged. Moreover, despite attention to practical rather than emotional considerations shaping one's scholarly identity, stress is understood as a salient emotion affecting doctoral students' wellbeing and resilience. Yet international doctoral students' affective stances toward their doctoral education and the impact they have on how they see themselves as developing scholars remain underexplored. The present study focuses on international doctoral students of Education in Finland as a group that needs to shape a scholarly identity under academic and sociocultural circumstances new to them. Focusing on their experience, this case study addresses the following research questions:

1) What sources of stress do international doctoral candidates of Education in Finland perceive during their doctoral training?

2) How is scholarly identity involved in response to perceived sources of stress? 


\section{Research methods}

\section{Participants}

Eleven IDS pursuing a research doctorate in Education participated in this case study. Their doctoral training took place within educational sciences at the universities of Eastern Finland, Jyväskylä, Lapland, Oulu, Tampere, and Turku. In the research doctorate model used by Finnish universities, the workload lies in accomplishing the doctoral research; this may be a source of stress, as university students are used to studying but have very little previous experience of conducting research. The participants were one man and ten women from China, Greece, Hong Kong, India, Japan, Namibia, Poland, Turkey, and Vietnam. Five of them were in the early (exploring the literature, designing the studies, collecting data, preparing the first manuscript), three in the middle (having submitted or published manuscripts), and three in the final stage (having submitted or published the last manuscript, preparing the dissertation, preparing for thesis defense) of their training.

\section{Research approach and data analysis}

The interviews took place from March to April 2018, in person and via Skype. The participants were reached by sending an invitation via the email list of the Finnish Multidisciplinary Doctoral Training Network on Educational Sciences (FinEd). The participants were informed of the content and aims of the study as well as their rights to anonymity, withdrawal of participation, and reading the final manuscript before its submission. Upon signing the informed consent form, the IDS participated in a semistructured interview in English (see Appendix 1). The interview addressed the participants' background and was based on literature on the concepts of scholarly identity and stress. The qualitative approach taken aimed to highlight how participants perceived their experiences and contextualized within social and relational dynamics at the university (Labuschagne 2003). The interviews were conducted by the first author, who at that time was a doctoral student herself, thus creating an interview climate of ease, closeness, and confidentiality. The interviews were audiorecorded (average 42.27 minutes) and transcribed (average 9.5 pages; Calibri, font 11, single-line spacing and a break between speaking turns) by the first author.

All authors became familiar with the transcripts, coded following the model of thematic analysis suggested by Braun and Clarke (2006). The first author coded the transcripts from the perspective of scholarly identity, while the second author coded them from the perspective of stress (see Tables 1, 2 and 3). This helped identify stressors and their relationship to scholarly identity negotiation, while it also enabled triangulation during the coding phase (Bogdan and Biklen 1998), as the similarities found in naming some codes were discussed with the third author. The codes were organized into themes, which were understood as abstract constructs capturing the meaning of units of textual data and identifying possible patterns at different levels of granularity (Guest et al. 2012). The main stressors were examined against the themes for scholarly identity. The recorded and transcribed data have not been altered, but repetitions in the selected excerpts are indicated by $[\ldots]$ for easier reading. 
Table 1 Data analysis for intrapersonal regulation

Intrapersonal regulation

\begin{tabular}{|c|c|c|c|}
\hline $\begin{array}{l}\text { Main } \\
\text { themes }\end{array}$ & Themes & Subthemes & Codes \\
\hline
\end{tabular}

Stress Expectations and demands Individual expectations

- Comparing self to others

- Lack of expertise

- Uncertainty in defining one's position

- Valuing ones' worth

- New environment

- Supervisor's expectations

- Overworking

Contextual demands

Personal resources

Identity Biographical trajectory The personal

New environment

Negotiating the self as a scholar

Academic responsibilities

Managing stress

Personal work-related resources

Positioning oneself as a doctoral candidate
- Balance between different roles

- Time management

- Background information

- Cultural values (not Finnish)

- Family situation

- Individual characteristics

- Individual values and beliefs

- Ties to home country

- Adapting

- Finnish culture

- Publications

- Teaching duties

- Writing

- Being proactive

- Being merciful to oneself

- Compassion

- Distracting oneself

- Doing things for oneself

- Giving oneself credit

- Negotiating stress with oneself

- Self-regulation

- Sense-making

- Expectations

- Learning goals

- Passion

- Motivation

- Career goals

- Professional values

- Affiliation with institution

- Comparing self to others

- Positioning

- Presentation of self to others

\section{Findings}

In this section, each perceived source of stress is discussed in relation to the ways scholarly identity was involved in response to stress.

\section{Intrapersonal regulation}

Intrapersonal regulation (10/11) involved a sense of conflict between internal and external personal and contextual demands, but also personal resources used to negotiate this conflict. 
Table 2 Data analysis for challenges in doing research

\begin{tabular}{|c|c|c|c|}
\hline Main themes & Themes & Subthemes & Codes \\
\hline \multirow[t]{4}{*}{ Stress } & \multirow[t]{2}{*}{ Prerequisites for research } & Practicalities & $\begin{array}{l}\text { - Collecting data } \\
\text { - Finding participants } \\
\text { - Office space } \\
\text { - Presenting one's work } \\
\text { - Publishing }\end{array}$ \\
\hline & & Funding & $\begin{array}{l}\text { - Competition } \\
\text { - Coping financially } \\
\text { - Uncertainty about the future }\end{array}$ \\
\hline & \multirow[t]{2}{*}{ Taking a toll } & Health & $\begin{array}{l}\text { - Cognitive presence of research } \\
\text { - Mental health } \\
\text { - Physical health }\end{array}$ \\
\hline & & Negative affect & $\begin{array}{l}\text { - Feeling inadequate } \\
\text { - Frustration }\end{array}$ \\
\hline \multirow[t]{4}{*}{ Identity } & \multirow[t]{4}{*}{ Becoming a researcher } & Being critical & $\begin{array}{l}\text { - Doubts and reservations } \\
\text { - Uncertainty } \\
\text { - Suggestions for improvement }\end{array}$ \\
\hline & & Learning to do research & $\begin{array}{l}\text { - Prioritizing } \\
\text { - Professional learning } \\
\text { - Realizing a research plan } \\
\text { - Material resources }\end{array}$ \\
\hline & & Practical challenges & $\begin{array}{l}\text { - Subsidizing } \\
\text { - Training } \\
\text { - Time constraints }\end{array}$ \\
\hline & & The $\mathrm{PhD}$ process & $\begin{array}{l}\text { - PhD as a process } \\
\text { - Feelings of reward } \\
\text { - Feeling creative } \\
\text { - Taking ownership of one's research }\end{array}$ \\
\hline
\end{tabular}

Participants (6/11) referred to expectations they had of themselves concerning becoming skilled at a particular field or method and investing more time than anticipated into their doctoral studies. By examining some of these expectations, some participants tried to make sense of how they themselves might be in the future, should they continue as researchers. For instance, talking about whether stress eases at a later time, IDS2 says:

So, they do not struggle $[\ldots]$ to grasp the basics $[\ldots]$ they enjoy more than they struggle. This is how I want to think about it, because otherwise I think that my motivation will drop dramatically, if I think that it will always be the same, hard and stressful and struggling.

This participant negotiates stress by taking a protective stance toward her motivation and assuming that the present stress she feels, due to her current lack of expertise, will be replaced by quality and enjoyment. The negotiation that takes place may temporarily fortify her scholarly identity against defeatism by envisioning what research may be like at a more advanced stage.

Stress from intrapersonal regulation further involved trying to determine one's own place. Nearly all (10/11) participants referring to how they saw themselves as doctoral students replied in a manner that vacillated between roles. The most self-reflective comment would be IDS10's: 
Table 3 Data analysis for lack of supportive networks

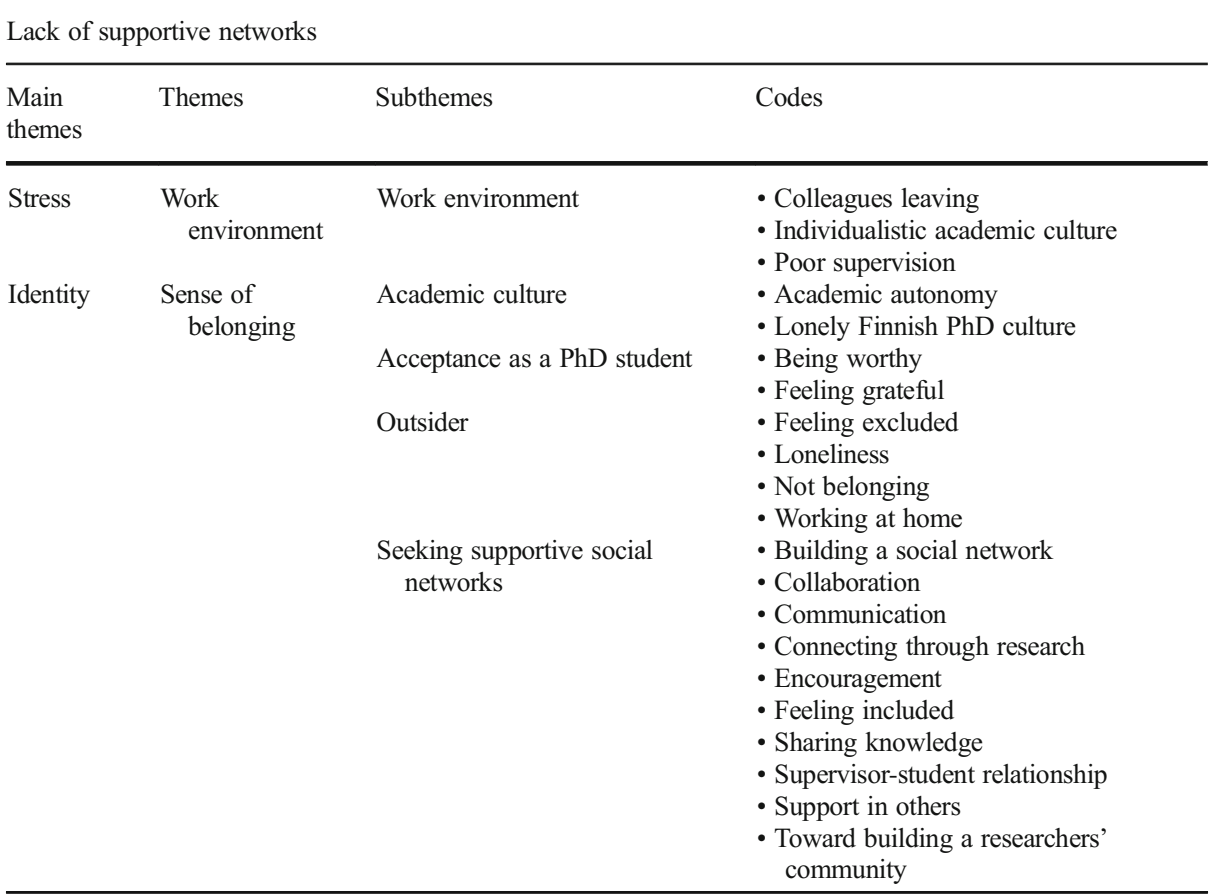

so that kind of identity question has been in my head all the time [...] I'm all the time somewhere between [...] I'm still kind of reluctant to say- to call myself a researcher, but I'm also reluctant to call yourself- myself a student. [...] If you don't have funding, you're not, uh, this tohtorikoulutettava [a salaried doctoral student] either, but you are always a student or a candidate, [...] it's a continuous, um, thinking, for me, but I think I'm somewhere in between all of these, uh, yeah, definitely. Which is- which is difficult, but it is also kind of liberating [laughs] not to be just this or that.

This excerpt echoes the ambivalence in other participants' answers, but it also highlights the in-between position doctoral candidates might feel they occupy as well as how being funded or not may affect the title or role one may decide upon for themselves. While the institution may be a safe place, participants were still unsure of how to describe themselves within their respective institutions.

A critical comparison of oneself as a scholar to others was also seen as a challenge (10/11). Despite this comparison being positive regarding their doctoral training, a few participants made an unintentional comparison between themselves and others concerning their professional values. For instance, being a researcher is not merely a job one does but a means of personal development. This value is echoed in IDS3's understanding that research is something "maybe you can feel personally connected to and give you this kind of sense of self-actualization, self-fulfillment." However, precisely because doing doctoral studies "is a very privileged life" (IDS3), one should remember that "teaching a bit and doing research a bit, like, together" (IDS3) as well as contributing to societal change are important aspects of research to uphold: 
For me, higher goal- I mean, the purpose of all academics do is, is really to contribute to, to social justice and to positive change. So, I've- what I've learned in these years that it's not unfortunately a goal for, for all people. Or not the major goal for all people involved in, in academia. (IDS10)

Scholarly identity may use others as reference for who one aims to become as a scholar and the purposes one identifies with doing research. The professional values doctoral candidates develop through their studies, but also through watching colleague's behavior, influence how they esteem what they are doing and the goals they set for themselves. Comparing oneself as a scholar to others was not seen as a source of stress per se; rather, it served participants as a way to express their appreciation of their post as doctoral students and position themselves as developing scholars in relation to perceived orientations in the academic world.

Participants abated the perceived stress from challenges in intrapersonal regulation by employing personal resources, like learning and career goals, their professional values, their passion, motivation, and self-discipline. For instance, IDS11 stresses her unflinching determination to complete her doctoral training and honor the sacrifices she has made. IDS1 claims that "[s] tress is necessary for development" and reminds herself that "[ she is] not doing it for... just for the money but also for [her] own meaning and also for, like, something [she] believe[s] in." For other participants, self-regulation, sense-making, and being merciful toward oneself helped participants view stress as a motivational force in their studies. Stress was seen as "a very positive aspect" that helped identifying what is important to one's life and one's research and "what it means to be involved in academia" (IDS10). Furthermore, seeing stress as "a motivation by itself" urges one to "try harder" and "become more competent and more efficient" as a result of that effort (IDS2). However, because "[stress] can be very destructive" (IDS2), it is important that one concentrates on the short-term (IDS2), allow themselves to learn through trial and error (IDS1), and take a step back when "getting completely overworked" (IDS9), especially in the beginning. The participants' stance toward stress may be a positive one, although they actively employed personal resources which came to bear on the progress of their research to manage perceived stress. By doing so, they attributed stress a positive influence on their studies and saw it as part of their scholarly identity enacted through their doctoral training and their participation in the academic environment.

\section{Challenges in doing research}

While finding participants, collecting data, publishing, and presenting one's work were part of research practicalities, the practical challenge of funding one's research was found to be rather stressful (8/11). Supporting oneself in a foreign country causes "financial stress" (IDS1) and receiving "a stipend that can barely [...] support your living" as a doctoral student is not the same as other "people earning money, like, real money by working" (IDS1). Moreover, receiving a grant from another country or not at all decreases one's sense of responsibility toward the Finnish institution or their positive attitude (e.g., IDS4, IDS7). These instances may create a belief that being a scholar is not as socially valid as doing other "real" jobs but also gives rise to discrepancies between those whose research is and is not financially recognized. IDS10, in particular, was vocal about funding being a pervasive concern that reflects "broader changes in society" and raises "a question of [...] what kind of research is prioritized." She adds:

that's the major concern. I think it's not just my concern. I see a lot of people around me also struggling with that. [...] Yeah, I've learned how difficult it is to get money, how 
many people are fighting for the money, which is- which made me also give up at some

point, because then I just though there's no point, no sense to do this.

While this participant later mentioned she would "try again maybe," other IDS might be too disheartened to do so. Funding was important for concentration on their studies, especially since they would not have to split their time among a full-time job, family, and doctoral training (e.g., IDS4, IDS5, IDS7, IDS8, IDS11). The difficulties and subsequent demotivation that occur from the stress to procure funding for one's research can be detrimental to the development of a resilient and focused scholarly identity.

In addition to funding or lack thereof, future prospects were found to be challenging for half of the participants (7/11). Participants had to cope with stress stemming from doubts, reservations (7/11), and uncertainty (6/11), which they came to see as inherent to being a researcher. Participants felt uncertain of their future development and opportunities to work as future researchers (e.g., IDS2, IDS3, IDS4, IDS11). Moreover, they pondered the significance of their study "for the actual educational context" (IDS7) as well as the validity of what they were doing and their skillset (IDS10). Looking at the issue more broadly, IDS10 explains that:

it's not just for doctoral students. I see also all the other academics and staff in university. [...] Teachers and researchers are never certain what they- often are uncertain about their next year work and such. So this is probably the major stress, stress-related factor.

It seems that to negotiate their scholarly identity, doctoral candidates need to be aware and, indeed, face their own insecurities about the importance of their research as well as the uncertainty of a secure future in academia. Overall, the participants seemed to accept the stress coming from such uncertainty, yet the uncertainty itself can deprive scholarly identity of a positive outlook regarding future prospects and the legitimacy of one's research interests.

From the perspective of scholarly identity, the importance of this theme lies in how the presence of stress in its negative form seems to impact the health of the participants as well as their emotional well-being. Some participants (4/11) commented on how their research is always cognitively present, making them feel so tired they "just want to completely shut down" (IDS1) or have "haunted" sleep (IDS6), because of unresolved research-related issues or the day of defending their dissertation (e.g., IDS2, IDS11). In addition, it causes feelings of "inner anxiety" for not working as efficiently, focused or self-disciplined as one might have wanted, leading one to "break down to some extent" (IDS3), and feel "emotionally agitated" (IDS3), "crazy" (IDS11), or guilty (IDS2, IDS11) when spending time on something else. Stress reaches farther, however, involving the body. IDS2 complained that her "back hurts a lot," IDS8 mentioned weight gain, due to lack of exercise, IDS10 talked about how "[s]tressrelated issues were manifesting [themselves] in a physical way," and IDS5 described her exhaustion:

The pressure of, em, especially during the data collection period, I was so exhausted and at one point I- I- I was so burn out and, and I started crying in front of the children. I didn't know, but my voice was gone... My voice was gone. I was- I was totally fatigued, you know, like tired, the whole body.

Not only working oneself too hard to realize a study but also pondering the reasons behind doing research in the first place can be stressful, with unanswered questions becoming "suffocating" and "stressful" questions, despite it being "important to keep asking these questions and also trying to find answers" (IDS10). 
The mental and physical toll stress can take on doctoral students could intensify frustration (6/11) and feelings of inadequacy (4/11). Frustration, for example, involved the futility of preparing funding applications in the beginning of one's doctoral training (IDS1) and past research-related experiences (IDS4). Further pressure may be applied by not feeling "competent enough for this" (IDS2) and "[i]nadequate in the concepts, in explaining the whole thing, in, uh, knowing [...] all the background and to make the research question, uh, impeccable" (IDS1). The degree to which one chooses to be consciously influenced by stress may lie with lifestyle choices (IDS2), yet its subconscious effects are not always perceived in time, and its subtle nature can be detrimental to scholarly identity negotiation. The process of shaping one's scholarly identity while completing one's doctoral studies may become infused with insecurities and fatigue that could affect not only the here and now of the doctoral experience but also long-term commitment to a career in academia. Trying to find meaning in one's research work and making sense of what doing research entails is part of scholarly identity negotiation. However, when this effort is a constant constraint or struggle for a doctoral student, scholarly identity itself might become too loaded with negative affect. Moreover, stress that becomes noticeable psychosomatically might render scholarly identity uncertain in terms of viability in the long run.

What seemed to counter such negative affect was participants' view of their doctoral training as a process $(8 / 11)$. They chose the words process, journey, and development to refer to their learning trajectories through doing research. This choice of words reflects the realization that learning to become a researcher is a slow and long process requiring milestones and skill development along the way. Moreover, this process involves deeper self-awareness and learning how to think like a researcher, as:

Now, slowly, I think I start building competencies that make me feel more, eh, of a young researcher than of a student, but I still have a long way to go, I think. (IDS2)

It is important to note that some participants regarded their learning trajectories as a process that can be creative (4/11) and rewarding (5/11). The conscious adoption of such an outlook on the process of learning through doctoral training is not only important for the personal growth of the individual candidate at the time of training but also for lasting professional empowerment. This is underlined by participants clearly taking ownership of their research (7/11). As IDS3 states, "I think it's for a student to be in charge of his or her studies, like, to take charge and not think that it's somebody else's study." Being "responsible and dedicated to your research" (IDS11) reflected participants' focus and belief of their accountability in doing research, regardless of the way they saw themselves as doctoral candidates. During this learning process, however, it seems important that boundaries be drawn in order to maintain healthy progression and enhance well-being, such as balancing between personal and academic life (e.g., IDS2, IDS5).

\section{Lack of supportive networks}

Supportive social networks, discussed by all participants, involved the academic culture, and lack of social and academic support from colleagues, supervisors, and peers. While autonomy over their studies was valued by the participants (6/11), most participants (10/11) remarked the "[1]oneliness features here" (IDS1) and the lack of "community as such within which you can really learn" when, "from all the education years," they are traversing "the most individualistic phase" (IDS2). These circumstances may give the impression that "you have to find everything 
on your own" (IDS2) and that "right now it seems a very lonely journey" (IDS9). More importantly, however, it detracts from the feeling that the doctoral candidate is "a part of something bigger" (IDS2) or that they could have "learned more or differently" (IDS8). Although this sense of not belonging by some participants was not viewed as a source of stress, but rather a challenge, it does shape scholarly identity in terms of beliefs. In particular, it shapes the belief that learning to be a researcher is an individualistic and lonely process, which may not necessarily be attached to a wider, meaningful view of the research field.

This loneliness and individualism may be moderated by the supervisor-candidate relationship. Supervisors become "[o]ne of [their] most important mentors" (IDS2), "a huge resource" (IDS9) providing support, trust, expert knowledge, guidance, professionalism, mediation between faculty and candidate, time to discuss conceptual and methodological topics, and motivation. However, the bond some participants shared with their supervisors went beyond a mere professional relationship, enhancing a sense of responsibility and motivation (e.g., IDS5, IDS9). The supervisor-candidate bond is not only important for doctoral students in the beginning of their doctoral training but also for the more advanced ones. However, lack of support or bad supervisor-candidate fit may accentuate candidates' feelings of doing unsupported working by themselves.

Beyond developing a relationship with one's supervisor, nurturing a sense of belonging involved actively seeking and providing a supportive social network. Commitment to an academic career might be enhanced by the perceived presence of an international community at the university (e.g., IDS4, IDS7, IDS9), lending participants' scholarly identity an international character which might be "good as a trade for a researcher" later in their career (IDS2). At the same time, however, the Finnish academic communities and their potential for learning should not be discounted, while a strictly international character might also have a negative impact on scholarly identity. As IDS1 remarks, "having a good social circle is also, uh, a good thing, uh, because you can share your concern, your stress, uh, the uncertainty"; yet acquaintances and friends of international backgrounds go abroad once more, making relationships seem transitory. Social networks being "term-limited" (IDS8) and energy-intensive (IDS2) could be a source of stress for some, as the interpersonal support system needs to maintained when there is not enough time and may, at times, seem futile, but it can be countered by active involvement in building a social network of one's own (8/11), encompassing academics and nonacademics (e.g., IDS1, IDS7, IDS9).

Especially concerning a social network of academics, communication (7/11) and collaboration (6/11) were found to be important for half of the participants, followed by connecting through research (4/11), building a researchers' community (4/11), and sharing knowledge (3/11). Communication mostly involved people at the university; it did not only involve the exchange of ideas or feedback (IDS2, IDS6, IDS9) but also the sharing and validation of stress in doctoral studies:

it's really nice to share my anxiety with other PhD students and then- it's really nice to know that others also have this kind of stress and anxiety, what I also have, so it's really nice. (IDS4)

Stress is viewed as a natural component of becoming a researcher, which can be discussed and countered by peers' insights. However, doctoral candidates might not be good at taking initiative to organize informal gatherings, thus contributing to a lack of peer supportive networks within and beyond the university. Among others, this might obstruct the flow of information one needs (e.g., conferences, administration), as others "don't even know what 
you know, so they don't even know what they should inform you about" (IDS2). This might be problematic for scholarly identity negotiation, since not only might it make one feel excluded but also cause the loss of opportunities for this negotiation to take place. Collaboration was important for "feel[ing] the stimulus of dynamics or conversations or discussions in a project" (IDS8) and taking advantage of experienced researchers' advice on one's work. Like peers becoming "a sounding board" for the doctoral candidate (IDS9), established researchers become the scaffolding for their professional development:

Eh, sometimes it just helps to hear how they think and it helps me a lot to frame also, uh, the ideas in my mind. [...] But, also, eh, another person with whom we have been collaborating, em, and he- his philosophical way of thinking- I mean, scientifically philosophical- It might sound contradictory, but it is not very much. (IDS2)

More experienced colleagues serve as catalysts and guides for contemplation of not only one's work and professional relationships but also the nature and meaning of doing research. In that regard, scholarly identity negotiation draws on the deeper thinking one does on one's own, whereby one learns to be at once a scientist and a philosopher. This deeper thinking is influenced by the ways of thinking used by expert others in close proximity as well as by international authoring partnerships that provide scholarly identity negotiation opportunities by means of conceptual and inspirational frames. Actively partaking in communication with peers and forging collaborative relationships with more knowledgeable researchers can help construct a sense of a research community that can teach how to negotiate or safeguard against stress. In the following chapter, the main issues arising from the findings are discussed.

\section{Discussion}

This case study addressed sources of stress as perceived by IDS of Education in Finnish universities and how scholarly identity is involved in response to them. The principal sources of stress were intrapersonal regulation, challenges in doing research, and lack of a supportive network. Intrapersonal regulation encompassed participants' concerns about becoming skilled, positioning themselves as young academics in training, and taking others a point of reference for their scholarly identity. Scholarly identity was employed through goals, values, and motivation to regulate one's reactions to stress and interpret stress as a positive element in their training. Challenges in doing research involved research practicalities, acquiring funding, and reservations about researcher career prospects. Participants' reaction to this source of stress was connected to accentuated feelings of inadequacy and frustration. To counter stress, scholarly identity was employed via participants' views of viewing the process of becoming a researcher as a longitudinal project, demanding constant development of skills, more profound thinking, increasing independence, and ownership of one's own research and progress. Lack of supportive networks concerned the absence or short-lived presence of personal and collegial relationships that can afford academic support and a stronger sense of membership. Scholarly identity involved the acceptance of stress as a shared experience and the knowledge that its negative influences can be moderated by insights, inspiration, and support found in members of the academic community. A noteworthy observation is that, while stress did have negative manifestations, participants largely regarded stress as positive, i.e., eustress, and a necessary part of their studies. 
One of the perceived sources of stress was intrapersonal regulation. The desire to become a skilled scholar, time investment and positioning oneself as a doctoral student in relation to the local academic context were informed by participants' professional orientations, motivations, and self-monitoring. This supports the finding that emotional aspects, like self-discipline, motivation, and interest, promote, rather than hinder, international doctoral students' studies (Sakurai et al. 2012). Contrary to Pyhältö et al. (2012b), who identified motivation and selfregulation in doctoral students as problems in general work processes that are rather difficult to solve, the findings of the present study suggest that international doctoral students in Education were very determined, and the positive outlook on stress as a motivator helped orient themselves in terms of learning, role, interests. The way participants understood themselves as professional subjects (Eteläpelto et al. 2014) drew on professional aspirations and interests (Cotterall 2015) and used internal resources (Anderson 2017; Evans and Stevenson 2010; Pyhältö et al. 2012b) helped regard stress as a motivational force in their studies. International doctoral students' high motivation, at least initially, has been seen in their proactive involvement in study abroad (Sakurai et al. 2012; Zhao et al. 2005), while active strategies on the part of doctoral students have been associated with reduced burn-out risk (Stubb et al. 2012). Despite the optimistic view of stress participants seemed to share, the choice for it to be treated as a constructive element indicates the need to foster international doctoral students' persistence in the long run.

Another perceived source of stress was challenges in doing research. Practical aspects of doing research and financial and occupational insecurity were found to affect scholarly identity (see also Ortlieb and Weis 2018). While higher education in Finland is not subject to tuition, IDS have frequently reported problems with finances and lack of research funding, among other departmental issues, as a hindering factor to their studies (Pyhältö et al. 2012b; Sakurai et al. 2012). Financial support affects doctoral students' retention, persistence, and timely completion of their doctoral degree (Ehrenberg et al. 2007; Zhou and Okahana 2019). Yet financial preconditions for doing doctoral studies were considered a problem by only one-fifth of the participants, while the problems participants did emphasize were rather pedagogical in nature (Pyhältö et al. 2012b). Pyhältö et al. (2012b) attributed these findings to most doctoral students registered for full-time studies trying hard to obtain funding from funds, foundations, and institutions. For some participants, having to strive for or lacking funding made scholarly identity feel invalid when comparing oneself to others with "real" jobs. It, further, caused them to question the legitimacy and relevance of their study within the educational contexts researched. Coupled with uncertainty about career prospects in academia, this may affect their outlook on not only present and future circumstances but also one's validity as a developing scholar. This uncertainty is interesting considering the higher levels of career interest IDS in Finland typically entertain in comparison to their native counterparts (Pyhältö et al. 2019).

The third perceived source of stress was the lack of supportive networks. Influential aspects of social inclusion at the university (e.g., information circulation, knowledge sharing, and project participation) were not always present, and participants reported a sense of loneliness in their doctoral training experience. Doctoral students experiencing stress and loneliness are more likely to face burnout and attrition (Cornér et al. 2017; Pyhältö et al. 2015). Research in Finland indicates that the percentage of doctoral students feeling outside a scholarly community is high (30\%), with those in Education feeling the most isolated in terms of membership, perhaps because of not completing their doctorate within a research group (Pyhältö et al. 2009). Moreover, unlike Finnish students, IDS have been found to not strongly associate with peers and other doctoral students, seemingly leaving them without close collegial support in 
case of supervisory challenges (Sakurai et al. 2012). In the present study, participants seemed to have developed positive relationships within their academic community, including mostly supervisors and other international students, but be preoccupied with how transient these relationships can be. This could attenuate a sense of belonging to the university, since it does not involve a close connection to Finnish counterparts in their academic community, and imbue the interpersonal aspect of scholarly identity with a sense of futility.

Some social networks helped participants with perceived sources of stress in their doctoral training, validated their membership with the university as an institution, and facilitated the exchange of ideas. This supports the suggestion made by Sakurai et al. (2012) to explain a lack of statistically significant association between broader communities and participants' satisfaction with their training or desire to drop out; more than the training, a sense of attachment, friendship, and general well-being may be experiences that relationships with peers and colleagues contribute toward. Scholarly identity negotiation may further involve the acceptance of stress as a shared experience and the knowledge that its negative influences could be moderated by insight, inspiration, and support found in members of the academic community, such as supervisors. In Finland, doctoral students in educational sciences reported supervisory challenges more frequently, perhaps because their background in pedagogy raises their awareness concerning educational practices and communication problems (Pyhältö et al. 2012b). The present findings corroborate the importance of doctoral supervisors for students' well-being; the satisfaction from the developed relationship derived from the expert knowledge and guidance participants felt they received, but also from the positive working relationship (Sidhu et al. 2014). Doctoral supervisors strongly influence how the personal and professional attributes of their students will be nurtured toward becoming contributing members of an academic community and how effectively the supervisory process and challenges are managed toward critical thinking and emancipation (Friedrich-Nel and Mac Kinnon 2019). Moreover, a functional supervisory relationship based on mutual trust, sensitivity to the student's needs, clear communication, constructive feedback, and explicit strategies for the completion of the doctoral degree are conducive to students' well-being, satisfaction with their doctoral training, and timely completion of their doctorate (Cornér et al. 2017; Pyhältö et al. 2015). It is worth mentioning, however, that firmer guidance might be more formative in the early years of IDS' training until they gain domain-specific expertise, strengthen feelings of self-efficacy and self-regulation, and abate feelings of loneliness (e.g., Pyhältö et al. 2012b).

Although stress may be negative, resulting from being unsuccessful in satisfying the personal or environmental demands (Szalma and Hancock 2008), more than half of the participants saw stress as a motivating aspect and necessary for development. It was regarded as an ever-present element of their doctoral training, yet one that facilitated their progress (e.g., setting deadlines for oneself), rather than paralyzed them. The findings show that experiencing stress as eustress and seeing stressors as challenges, rather than negative events, become resources themselves for succeeding in one's doctoral training. The findings are in line with O'Sullivan (2011) who argued that eustress supports studying and working on assignments, thus heightening productivity and successful completion of assignments and exams. Having such an outlook on stress might be encouraging for the overall development and acculturation of IDS as young scholars, yet the need for self-regulation skills as well as balance between demands and resources should be paid attention to by both institutional and individual initiative. 


\section{Limitations}

The study explored stress and scholarly identity, focusing on IDS in educational sciences in Finland. The number of the interviews, while not high, was sufficient for code saturation (e.g., Baker and Edwards 2012). To see if the findings are reflective of other IDS's experiences, future research should include doctoral students in other countries and different disciplines. Moreover, follow-up interviews with the participants of the present study could yield interesting new insights, since most of them were in the early stage of their doctoral training. Another limitation is that the interviews took place in English, which was a second or foreign language for most of the participants. However, all participants were highly proficient in English and used to discussing research-related matters using English. As doctoral programs vary in implementation across and within universities and countries, detailed practical suggestions may be hard to make. However, it can be suggested that information about access to mental healthcare services be more readily available to doctoral students. Moreover, doctoral programs could create a more supportive environment offering the students activities validating their membership. Finally, universities may need to attend to special challenges posed by the in-between state of doctoral students (i.e., neither students nor researchers) by acknowledging their status in the academic career track as researchers in training in formal documents (e.g., using the term "doctoral researcher").

Acknowledgments The authors would like to thank the Finnish Multidisciplinary Doctoral Training Network on Educational Sciences (FinEd) for disseminating the call for the interviews. Their gratitude is extended to the international doctoral students who participated in this study.

Funding Information Open access funding provided by University of Helsinki including Helsinki University Central Hospital.

\section{Compliance with ethical standards}

Conflict of interest The authors declare that they have no conflict of interest.

\section{Appendix 1. Interview questions}

\section{Warming up}

- Which university are you from?

- Where are you from?

- How many years have you been a doctoral student?

- At which stage of your doctoral training are you at the moment?

- Why/How did you choose Finland for your doctoral studies?

- Why did you choose education as your field of research?

\section{Interview questions}

1. How do you see yourself as a doctoral student? 
- Would that be the term you would use for yourself?

2. How do you see yourself as a young researcher?

3. What do you see as the (primary) responsibilities of a doctoral student?

4. What do you think you have learned so far? (as a doctoral student or young researcher in training)

5. What do you think are some of the constraints and resources at your current workplace?

- What about Finnish doctoral education and Finnish higher education institutes?

- How about your current phase/stage of doctoral training?

6. What are your views on life as a researcher?

7. How do you see yourself as a (developing) scholar?

- Where do you draw your motivation from?

- What have you found to be difficult during your doctoral training?

- What have you found to be easier during your doctoral training?

8. How do you see stress as a component of your doctoral training/of your life as a doctoral student?

- How would you describe the presence of stress in your life?

- How would you describe the presence of stress in your doctoral training?

9. What do you find to be the most stressful?

10. How do you cope with stress?

11. What sort of coping strategies have you developed?

- What sort of coping strategies have you found to be effective or helpful?

12. How do you see the balance between your doctoral studies and personal life?

- How has your doctoral training affected or influenced your private life?

13. How would you describe your relationship with

- writing?

- your supervisor?

- other doctoral students?

14. How do you feel you are part of a local and international community? Part of your field of research?

15. How does your funding situation affect/influence the progression of your studies and your own development?

16. What are some of the positive emotions you have associated with your studies? 
- Have these positive emotions been somehow heightened by stress?

\section{Closing}

- What are your future plans?

- What support do you think you would benefit from?

- What do you think would help you complete your doctoral training? (in the beginning or middle)

- What do you think would have helped you throughout your doctoral training? (toward the end)

Open Access This article is distributed under the terms of the Creative Commons Attribution 4.0 International License (http://creativecommons.org/licenses/by/4.0/), which permits unrestricted use, distribution, and reproduction in any medium, provided you give appropriate credit to the original author(s) and the source, provide a link to the Creative Commons license, and indicate if changes were made.

\section{References}

Aittola, H. (2017). Doctoral education reform in Finland - institutionalized and individualized doctoral studies within European framework. European Journal of Higher Education, 7(3), 309-321. https://doi.org/10.1080/21568235.2017.1290883.

Amran, N. N., \& Ibrahim, R. (2012). Academic rites of passage: reflection on a PhD journey. Procedia - Social and Behavioral Sciences, 59, 528-534. https://doi.org/10.1016/j.sbspro.2012.09.310.

Anderson, T. (2017). The doctoral gaze: foreign $\mathrm{PhD}$ students' internal and external academic discourse socialization. Linguistics and Education, 37, 1-10. https://doi.org/10.1016/j.linged.2016.12.001.

Austin, A. E. (2002). Preparing the next generation of faculty: graduate school as socialization to the academic career. The Journal of Higher Education, 73(1), 94-122. https://doi.org/10.1353/jhe.2002.0001.

Baker, S. E., \& Edwards, R. (2012). How many qualitative interviews is enough? Expert voices and early career reflections on sampling and cases in qualitative research. National Centre for Research Methods Review Paper. Retrieved from http://eprints.brighton.ac.uk/11632/1/how_many_interviews.pdf.

Baptista, A. V. (2011). Challenges to doctoral research and supervision quality: a theoretical approach. Procedia Social and Behavioral Sciences, 15, 3576-3581. https://doi.org/10.1016/j.sbspro.2011.04.338.

Baum, A., Revenson, T. A., \& Singer, J. E. (Eds.). (2001). Handbook of Health Psychology. Mahwah, NJ: Lawrence Erlbaum Associates.

Bogdan, R., \& Biklen, S. K. (1998). Qualitative research for education: An introduction to theory and methods. Boston, MA: Allyn and Bacon.

Braun, V., \& Clarke, V. (2006). Using thematic analysis in psychology. Qualitative Research in Psychology, 3(2), 77-101. https://doi.org/10.1191/1478088706qp063oa.

Cantwell, R. H., Scevak, J. J., Bourke, S., \& Holbrook, A. (2012). Identifying individual differences among doctoral candidates: a framework for understanding problematic candidature. International Journal of Educational Research, 53, 68-79. https://doi.org/10.1016/j.ijer.2012.02.001.

Coffman, K., Putman, P., Adkisson, A., Kriner, B., \& Monaghan, C. (2016). Waiting for the expert to arrive: Using a community of practice to develop the scholarly identity of doctoral students. International Journal of Teaching and Learning in Higher Education, 28(1), 30-37 Retrieved from http://www.isetl. org/ijtlhe/past $2 . \mathrm{cfm} ? \mathrm{v}=28 \& \mathrm{i}=1$.

Cornér, S., Löfström, E., \& Pyhältö, K. (2017). The relationships between doctoral students' perceptions of supervision and burnout. International Journal of Doctoral Studies, 12, 91-106 Retrieved from http://www. informingscience.org/Publications/3754.

Cotterall, S. (2013). More than just a brain: Emotions and the doctoral experience. Higher Education Research \& Development, 32(2), 174-187. https://doi.org/10.1080/07294360.2012.680017. 
Cotterall, S. (2015). The rich get richer: international doctoral candidates and scholarly identity. Innovations in Education and Teaching International, 52(4), 360-370. https://doi.org/10.1080/14703297.2013.839124.

Devonport, T. J., \& Lane, A. M. (2014). In it together: dyadic coping among doctoral students and partners. Journal of Hospitality, Leisure, Sport \& Tourism Education, 15, 124-134. https://doi.org/10.1016/j. jhlste.2014.08.002.

Ehrenberg, R. G., Jakubson, G. H., Groen, J. A., So, E., \& Price, J. (2007). Inside the black box of doctoral education: what program characteristics influence doctoral students' attrition and graduation probabilities? Education Evaluation and Policy Analysis, 29(2), 134-150. https://doi.org/10.3102/0162373707301707.

Eteläpelto, A., Vähäsantanen, K., Hökka, P., \& Paloniemi, S. (2014). Identity and agency in professional learning. In S. Billett, C. Harteis, \& H. Gruber (Eds.), International Handbook of Research in Professional and Practice-based Learning (pp. 645-672). Dordrecht: Springer.

Evans, C., \& Stevenson, K. (2010). The learning experiences of international doctoral students with particular reference to nursing students: a literature review. International Journal of Nursing Studies, 47, 239-250. https://doi.org/10.1016/j.ijnurstu.2009.05.025.

Finnish Ministry of Education and Culture. (2011). Laadukas, kansainvälinen, profiloitunut ja vaikuttava yliopisto - ehdotus yliopistojen rahoitusmalliksi vuodesta 2013 alkaen [High-quality, profilised and effective international university - Proposal for a reform of the university financing model from 20. Retrieved from http://urn.fi/URN:ISBN:978-952-263-086-5.

Finnish Ministry of Education and Culture. (2015). Ehdotus yliopistojen rahoitusmalliksi 2017 alkaen. Opetus- ja kulttuuriministeriön työryhmämuistioita ja selvityksiä 2015:19 [Proposal for the funding model of universities as of 2017]. Retrieved from http://julkaisut.valtioneuvosto.fi/bitstream/handle/10024/75157/tr19.pdf.

Folkman, S. (2008). The case for positive emotions in the stress process. Anxiety, Stress and Coping, 21(1), 3-14. https://doi.org/10.1080/10615800701740457.

Friedrich-Nel, H., \& Mac Kinnon, J. (2019). The quality culture in doctoral education: establishing the critical role of the doctoral supervisor. Innovations in Education and Teaching International, 56(2), 140-149. https://doi.org/10.1080/14703297.2017.1371059.

Guest, G., MacQueen, K. M., \& Namey, E. E. (2012). Applied thematic analysis. Thousand Oaks, CA: Sage Publications.

Hakala, J. (2009). The future of the academic calling? Junior researchers in the entrepreneurial university. Higher Education, 52(7), 173-190 Retrieved from https://www.jstor.org/stable/40269115\%0D.

Joshi, V. (2005). Stress: From burnout to balance. London: Sage Publications.

Kovalcikiene, K., \& Buksnyte-Marmienea, L. (2015). Towards an understanding of doctoral students' professional identity complexity. Procedia - Social and Behavioral Sciences, 191, 2693-2698. https://oi. org/10.1016/j.sbspro.2015.04.603.

Kupriyanov, R., \& Zhdanov, R. (2014). The eustress concept: problems and outlooks. World Journal of Medical Sciences, 11(12), 179-185. https://doi.org/10.5829/idosi.wjms.2014.11.2.8433.

Kyriacou, C. (1987). Teacher stress and burnout: an international review. Educational Research, 29(2), 146-152. https://doi.org/10.1080/0013188870290207.

Labuschagne, A. (2003). Qualitative research - airy fairy or fundamental? The Qualitative Report, 8(1).

Laufer, M., \& Gorup, M. (2018). The invisible others: stories of international doctoral student dropout. Higher Education, 76, 1-17. https://doi.org/10.1007/s10734-018-0337-z.

Lazarus, R. S., \& Folkman, S. (1984). Stress, appraisal and coping. New York, NY: Springer.

Levecque, K., Anseel, F., De Beuckelaer, A., Van der Heyden, J., \& Gisle, L. (2017). Work organization and mental health problems in PhD students. Research Policy, 46, 868-879. https://doi.org/10.1016/j.respol.2017.02.008.

Linden, W. (2005). Stress management. From basic science to better practice. Thousand Oaks, CA: Sage Publications.

Lovallo, W. R. (2005). Stress \& Health: biological and psychological interactions. Thousand Oaks, CA: Sage Publications, Inc.. https://oi.org/10.4135/9781452233543.n3.

Meijers, F. (2002). Career learning in a changing world: the role of emotions. International Journal for Advancement of Counselling, 24(3), 149-167. https://oi.org/10.1023/A:1022970404517.

Mesurado, B., Richaud, M. C., \& Mateo, N. J. (2016). Engagement, flow, self-efficacy, and eustress of university students: a cross-national comparison between the Philippines and Argentina. The Journal of Psychology, 150(3), 281-299. https://doi.org/10.1080/00223980.2015.1024595.

O'Sullivan, G. (2011). The relationship between hope, eustress, self-efficacy, and life satisfaction among undergraduates. Social Indicators Research, 101(1), 155-172. https://doi.org/10.1007/s11205-010-9662-z.

Ortlieb, R., \& Weis, S. (2018). What makes academic careers less insecure? The role of individual-level antecedents. Higher Education, 76, 571-587. https://doi.org/10.1007/s10734-017-0226-X.

Peura, M., \& Jauhiainen, A. (2018). Tohtoriopintojen monet merkitykset suomalaisille ja ulkomaalaisille jatkoopiskelijoille [The many meanings of doctoral studies for Finnish and foreign doctoral students]. Aikuiskasvatus, 3, 223-236. 
Pyhältö, K., Stubb, J., \& Lonka, K. (2009). Developing scholarly communities as learning environments for doctoral students. International Journal for Academic Development, 14(3), 221-232. https://doi.org/10.1080 $/ 13601440903106551$.

Pyhältö, K., Nummenmaa, A. R., Soini, T., Stubb, J., \& Lonka, K. (2012a). Research on scholarly communities and the development of scholarly identity in Finnish doctoral education. In S. Ahola \& D. M. Hoffman (Eds.), Higher education research in Finland (pp. 337-354). Jyväskylä: Jyväskylä University Press.

Pyhältö, K., Toom, A., Stubb, J., \& Lonka, K. (2012b). Challenges of becoming a scholar: a study of doctoral students' problems and well-being. International Scholarly Research Network ISRN, Education, 934941. https://doi.org/10.5402/2012/934941.

Pyhältö, K., Vekkaila, J., \& Keskinen, J. (2015). Fit matters in the supervisory relationship: doctoral students and supervisors perceptions about the supervisory activities. Innovations in Education and Teaching International, 52(1), 4-16. https://doi.org/10.1080/14703297.2014.981836.

Pyhältö, K., Peltonen, J., Castelló, M., \& McAlpine, L. (2019). What sustains doctoral students' interest? Comparison of Finnish, UK and Spanish doctoral students' perceptions. Compare: A Journal of Comparative and International Education. https://doi.org/10.1080/03057925.2019.1585229.

Russell-Pinson, L., \& Harris, M. L. (2019). Anguish and anxiety, stress and strain: attending to writers' stress in the dissertation process. Journal of Second Language Writing, 43, 63-71. https://doi.org/10.1016/j. jslw.2017.11.005.

Sakurai, Y., Pyhältö, K., \& Lindblom-Ylänne, S. (2012). Factors affecting international doctoral students' academic engagement, satisfaction with their studies, and dropping out. International Journal for Researcher Development, 3(2), 99-117. https://doi.org/10.1108/17597511311316964.

Schneiderman, N., Ironson, G., \& Siegel, D. (2005). Stress and health: psychological, behavioural, and biological determinants. Annual Review of Clinical Psychology, 1, 607-628. https://doi.org/10.1146/annurev. clinpsy.1.102803.144141.

Shapero, B. G., \& Hankin, B. L. (2009). Stress in adolescence: an examination of theories and methods. In P. Heidenreich \& I. Prüter (Eds.), Handbook of stress: Causes, effects and control (pp. 367-385). New York, NY: Nova Science Publishers, Inc..

Sidhu, G. K., Kaur, S., Fook, C. Y., \& Yunus, F. W. (2014). Postgraduate supervision: comparing student perspectives from Malaysia and the United Kingdom. Procedia - Social and Behavioral Sciences, 123, 151159. https://doi.org/10.1016/j.sbspro.2014.01.1409.

Stubb, J., Pyhältö, K., \& Lonka, K. (2012). The experienced meaning of working with a PhD thesis. Scandinavian Journal of Educational Research, 56(4), 439-456. https://doi.org/10.1080 /00313831.2011.599422.

Szalma, J. L., \& Hancock, P. A. (2008). Performance under stress. Aldershot: Ashgate.

Ursin, H., \& Eriksen, H. R. (2004). The cognitive activation theory of stress. Psychoneuroendocrinology, 29(5), 567-592. https://doi.org/10.1016/S0306-4530(03)00091-X

Vipunen, Education Statistics Finland. (2017). Retrieved from https://vipunen.fi/en-gb/_layouts/15/xlviewer. aspx?id=/en-gb/Reports/Yliopistokoulutuksen tutkinnot-näkökulma-vuosi_EN.xlsb.

Zhao, C.-M., Kuh, G. D., \& Carini, R. M. (2005). A comparison of international student and American student engagement in effective educational practices. Journal of Higher Education, 76(2), 209-231.

Zhou, E., \& Okahana, H. (2019). The role of department supports on doctoral completion and time-to-degree. Journal of College Student Retention: Research, Theory \& Practice, 20(4), 511-529. https://doi.org/10.1177 /1521025116682036.

Publisher's note Springer Nature remains neutral with regard to jurisdictional claims in published maps and institutional affiliations.

\section{Affiliations}

\section{Sotiria Pappa ${ }^{1}$ - Mailis Elomaa ${ }^{2}$ - Satu Perälä-Littunen ${ }^{3}$}

1 Faculty of Educational Sciences, University of Helsinki, Siltavuorenpenger 1A, Psychologicum, FI00014 Helsinki, Finland

2 Ruusupuisto RUU 2B, Alvar Aallon katu 9, University of Jyväskylä, FI-40014, PL 35 Jyväskylä, Finland

3 Ruusupuisto RUU C221, Alvar Aallon katu 9, University of Jyväskylä, FI-40014, PL 35 Jyväskylä, Finland 